BMJ Paediatrics Open

\title{
Complementary feeding intervention on stunted Guatemalan children: a randomised controlled trial
}

\author{
Boris Martinez, ${ }^{1}$ Meghan Farley Webb, ${ }^{1}$ Ana Gonzalez, ${ }^{2}$ Kate Douglas, ${ }^{1,3}$ \\ Maria del Pilar Grazioso, ${ }^{2}$ Peter Rohloff ${ }^{1,4}$
}

To cite: Martinez $B$, Webb MF, Gonzalez A, et al. Complementary feeding intervention on stunted Guatemalan children: a randomised controlled trial. BMJ Paediatrics Open 2018;2:e000213. doi:10.1136/ bmjpo-2017-000213

- Additional material is published online only. To view please visit the journal online (http://dx.doi.org/10.1136/ bmjpo-2017-000213).

Received 9 0ctober 2017 Revised 22 January 2018 Accepted 15 March 2018
Check for updates

'Wuqu' Kawoq I Maya Health Alliance, Santiago Sacatepéquez, Guatemala ${ }^{2}$ Department of Psychology, Universidad del Valle de Guatemala, Guatemala City, Guatemala

${ }^{3}$ School of Medicine, Washington University in St. Louis, St. Louis, Missouri, USA

${ }^{4}$ Division of Global Health Equity, Brigham and Women's Hospital, Boston, Massachusetts, USA

Correspondence to Peter Rohloff; prohloff@bwh. harvard.edu

\section{ABSTRACT \\ Objective/background Guatemala's indigenous Maya population has one of the highest rates of childhood stunting in the world. The goal of this study was to examine the impact of an intensive, individualised approach to complementary feeding education for caregivers on feeding practices and growth over usual care.}

Design An individually randomised (1:1 allocation ratio), parallel-group superiority trial, with blinding of study staff collecting outcome data.

Setting Rural Maya communities in Guatemala. Participants 324 children aged 6-24 months with a height-for-age Z score of less than or equal to $-2.5 \mathrm{SD}$ were randomised, 161 to the intervention and 163 to usual care.

Interventions Community health workers conducted home visits for 6 months, providing usual care or usual care plus individualised caregiver education.

Main outcomes measures The main outcome was change in length/height-for-age Z score. Secondary outcomes were changes in complementary feeding indicators.

Results Data were analysed for 296 subjects (intervention 145, usual care 151). There was a nonsignificant trend to improved growth in the intervention arm (length/height-for-age Z score change difference $0.07(95 \% \mathrm{Cl}-0.04$ to 0.18$))$. The intervention led to a $22 \%$ improvement in minimum dietary diversity (RR 1.22 , $95 \% \mathrm{Cl} 1.11$ to 1.35 ) and a $23 \%$ improvement in minimal acceptable diet (RR 1.23, 95\% Cl 1.08 to 1.40) over usual care.

Conclusions Complementary feeding outcomes improved in the intervention arm, and a non-significant trend towards improved linear growth was observed. Community health workers in a low-resource rural environment can implement individualised caregiver complementary feeding education with significant improvements in child dietary quality over standard approaches.

Clinical trial registration

number NCT02509936. Stage: Results

\section{INTRODUCTION}

Stunting, or low length/height-for-age, is the most common paediatric growth disorder worldwide, affecting $30 \%$ of children under 5
What is known about the subject?

Stunting is the most common paediatric growth disorder, and Guatemala has one of the highest rates of stunting in the world.

- In Guatemala's indigenous Maya population, and elsewhere in the world, stunting correlates with poor dietary quality, especially dietary diversity.

- Standardised complementary feeding messaging to caregivers is a common strategy to improve dietary diversity, but effectiveness is variable.

\section{What this study hopes to add?}

An intensive, individualised caregiver education approach can improve dietary outcomes in stunted children more than usual care based on standard feeding messaging.

- Individualised caregiver nutrition education may better engage caregivers in problem-solving and creative resource utilisation, leading to more effective. behaviour -change and improved feeding practices.

- Enhanced caregiver nutrition education can improve the impact of food rations and utilization of local food resources for children.

years. ${ }^{12}$ Although stunting is a complex condition influenced by numerous social and environmental factors, interventions to promote adequate complementary feeding practices in the first 2-3 years of life are the cornerstone of prevention and management. ${ }^{3-6}$

In Guatemala, which has the highest rate of stunting in the Western Hemisphere, intensive public and private sector efforts, focused especially on provision of micronutrients, complementary foods and counselling for caregivers, have reduced the national rate of stunting to around $50 \%{ }^{7}$ However, improvements have been slower for the country's indigenous Maya population, where stunting often exceeds $70 \%$ and feeding indicators remain poor despite strong agricultural production. ${ }^{8-12}$ This suggests 
that current complementary feeding education interventions-which, as in most low-income and middle-income countries, involve community health workers (CHWs) providing generic, age-based complementary feeding recommendations ${ }^{5}$ - may be inefficient in promoting caregiver behaviour change.

In this study, we hypothesised that an individualised approach to complementary feeding education would improve feeding practices more than usual care based on generic key feeding recommendations. We individually randomised child-caregiver dyads (children aged 6-24 months) to 6 months of usual care, which included generic age-based complementary feeding messages from CHWs, versus individualised complementary feeding education, which used structured interviews, 24-hour dietary recalls and open-ended goal-setting questions to promote incremental caregiver-initiated dietary changes. We evaluated impact of this intervention on growth and on feeding indicators.

\section{METHODS}

\section{Study context}

This study was conducted in collaboration with Maya Health Alliance (MHA), a primary care organisation working in rural Maya communities. MHA's supplementary nutrition programme, where CHWs provide home visits for 6 months to stunted children (aged 6-24 months) and their caregivers, ${ }^{13}$ provided the pragmatic study framework, including the 6-month timeline for assessing outcomes. The study was conducted in one municipality, Tecpán (population 95 000), in a settlement cluster of rural agricultural Kaqchikel Maya families. The study was conducted according to the principles in the Declaration of Helsinki.

\section{Trial design and participants}

This was a single-centre, individually randomised (1:1 allocation ratio), parallel-group superiority trial to compare individualised complementary feeding education to usual care (Clinicaltrials.gov Identifier: NCT02509936). Subjects were eligible if they were aged 6-24 months with a length/ height-for-age $\mathrm{Z}$ score (LAZ/HAZ) of less than or equal to $-2.5 \mathrm{SD}$ on WHO growth standards. ${ }^{14}$ Exclusion criteria were acute malnutrition (weight-for-length/height $\mathrm{Z}$ score (WLZ/WHZ) of less than or equal to $-2 \mathrm{SD}$ ) or severe medical illness. Study interventions (intervention, usual care) were delivered by two teams of two MHA CHWs. Prior to study training, CHWs were randomly assigned to their team and training for each team was conducted separately. One team provided usual care only and one team provided intervention arm care only.

Subjects were screened and recruited by a bilingual (Spanish/Kaqchikel Maya) study nurse not otherwise involved in the intervention. For caregivers consenting to participate, informed written consent was obtained. Study data were collected in two separate study visits at months 0 and 6 of enrolment by a study nurse blinded to subject allocation. All data were captured on paper forms and double entered in REDCap. ${ }^{15}$ For anthropometric measures and diet recalls, study nurses were trained using standard methods by a supervising study physician. ${ }^{16}{ }^{17}$ All anthropometric measurements were completed in triplicate. Weight was measured to the nearest $0.1 \mathrm{~kg}$ with the use of a Seca 310 hanging scale (Seca, Hamburg, Germany), and length/height was measured to the nearest $0.1 \mathrm{~cm}$ with the use of a locally constructed portable length board according to the Unicef specifications. ${ }^{18}$ Ongoing quality control via data review and random audits of in-field operations were performed by a study physician as described in more detail in the online Supplementary file 1.

\section{Study interventions and procedures}

For subjects in both study arms, the study duration was 6 months. The usual care arm was modelled on the Guatemalan government's 'Zero Hunger' guidelines for community-based nutrition ${ }^{19}$ and delivered by CHWs from the partnering organisation. Under usual care, caregivers and children received monthly home visits from the CHWs for growth monitoring, provision of multiple micronutrient powder supplement, a biweekly food ration and complementary feeding messages based on WHO recommendations. ${ }^{17}$ In the intervention arm, in addition to the above usual care, subjects received a monthly visit from a separate CHW team, who conducted a structured dietary recall and then reviewed individual data from the recall on continued breastfeeding, complementary food consistency, meal frequency and food diversity with the primary caregiver to develop an individualised feeding plan. CHWs in both arms worked independently and had no interaction with study nurses who collected outcome data. Additional detailed description of the intervention and usual care are provided in the online Supplementary file.

\section{Study outcomes}

The primary study outcome was change in length/heightfor-age $\mathrm{Z}$ score. ${ }^{14}$ Secondary outcomes derived from WHO population-level feeding indicators were minimum dietary diversity, minimum meal frequency and minimal acceptable diet. ${ }^{17}$ Definitions used for calculating these indicators are provided in the online Supplementary table 1. Additional details on collection of anthropometric and dietary recall data are provided in the online Supplementary file.

\section{Sample size calculation and randomisation}

Target sample size was determined by a power calculation based on pilot data for the primary outcome, where we observed a change in LAZ/HAZ of approximately $0.3 \mathrm{SD}$. Therefore, using a hypothesised difference in LAZ/HAZ between groups of 0.3 , with alpha of 0.05 , power of $80 \%$ and allowing $15 \%$ lost to follow-up, we planned to enrol 160 children per group. 
Simple randomisation was performed using a computer-generated random number list. A study staff member not involved in the subject recruitment, administered the list and provided the appropriate allocation from the random sequence. As a behavioural intervention, subjects and CHWs were aware of their group assignment. However, informed consent and study protocol documents described group differences generically in terms of visit frequency and CHW contact hours. Furthermore, each CHW team was trained separately, worked independently and was not informed of the details of the other team's work. Study nurses collecting baseline and outcome data were blinded to allocation.

\section{Statistical analyses}

Descriptive statistics for each group were calculated using Stata V.13. Family poverty scores were calculated with a validated numerical scoring system commonly used in Guatemala, with lower numbers corresponding to worse poverty likelihood (possible score range: 0-100). As a point of reference, a family poverty score of 45-49 corresponds to a $52 \%$ likelihood of living under US $\$ 1.25$ per day, whereas a score of 25-29 corresponds to a 90\% likelihood..$^{20}$ For study outcomes, differences between groups were assessed using the Student's t-test for continuous variables and relative risks (RR) with 95\% CI for categorical variables. Analysis was by intention-to-treat, except where subjects were lost to follow-up and outcome data could not be obtained. We also conducted exploratory bivariate analysis of the primary and secondary outcomes by variables that we specified in advance as likely to modify growth and feeding indicators (maternal parity $(\leq 2,>2)$, maternal education (none vs some formal education), gender, number of under-five children in the home (1, $2,>3)$ ), as well as subject variables at baseline that could theoretically modify the impact of the intervention on both outcomes (baseline length-for-age quintiles, household socioeconomic status and age at study enrolment).

Exploratory analysis was further extended with a hierarchical linear model (MIXED function in Stata V.13) for change in LAZ/HAZ. This allowed us to investigate the impact of individual subject-level variation on the primary study outcome and to estimate the effect of individual covariates on change in LAZ/HAZ. Our fully specified model included fixed effects for study time (before and after intervention), age at enrolment, study arm, significant covariates from the bivariate analysis and random effects to account for individual subject-level correlation. We subsequently reduced the model by removing non-significant covariates using serial likelihood ratio tests as recommended by West $e t a l^{21}$

\section{RESULTS}

Subject enrolment and baseline characteristics

Eligible participants were recruited from August 2015 to February 2016. Final study participants exited the study in September 2016. A total of 324 children were enrolled and underwent randomisation (control arm 163, intervention arm 161; figure 1). Baseline demographic and clinical features of participants in the two study arms were well balanced (table 1). Differences in baseline LAZ/HAZ and feeding indicators are stratified by prespecified covariates where significant (LAZ/HAZ by gender $(\mathrm{p}=0.0002)$ and number of children under-five $(\mathrm{p}=0.02)$, minimum meal frequency by maternal education $(\mathrm{p}=0.001))$.

Loss to follow-up was 7\% (12 subjects) in the control arm and $10 \%$ (16 subjects) in the intervention arm (figure 1). Subjects lost to follow-up had similar demographic characteristics as those who completed the study, except for significantly lower LAZ/HAZ and higher WLZ/WHZ at baseline (online Supplementary table 2).

\section{Intervention implementation details}

Participants in the intervention arm received a mean of $5.69 \pm 0.95$ home sessions (93.8\% of 966 planned sessions), with a mean visit duration of $43.06 \pm 10.97 \mathrm{~min}$. Participants in the control arm received a mean of $5.81 \pm 0.78$ home sessions (94.4\% of 978 planned sessions), with a mean visit duration of $19.75 \pm 7.18 \mathrm{~min}$.

\section{Outcomes}

The analysis of primary and secondary outcomes was by intention-to-treat. Sixteen subjects in the intervention arm and 12 in the control arm were lost to follow-up and exit study data were not available. Three subjects discontinued treatment but were included in the intention-totreat analysis. Therefore, the final number of subjects included in the analysis was 296 (figure 1).

For primary growth outcomes (table 2), the change in LAZ/HAZ at 6 months favoured the intervention arm, but did not reach statistical significance (LAZ/ HAZ change difference 0.07 (95\% CI -0.04 to 0.18$)$ ). WAZ and WLZ/WHZ declined over 6 months in both study arms, but more in the control arm, resulting in a non-significant trend favouring the intervention arm (WAZ change difference 0.08 (95\% CI -0.02 to 0.19 ); WLZ/WHZ change difference $0.08(95 \%$ CI -0.08 to $0.24)$ ).

For secondary feeding indicator outcomes (table 3), minimum dietary diversity (adequate number of food groups per day) improved 22\% (RR 1.22, 95\% CI 1.11 to 1.35 ) in the intervention, with an absolute difference of $16.9 \%$ (95\% CI $8.9 \%$ to $25.0 \%$ ). Minimal acceptable diet (composite of adequate dietary diversity and meal frequency) improved 23\% (RR 1.23, 95\% CI 1.08 to 1.40 ), with an absolute difference of $15.9 \%$ (95\% CI $6.4 \%$ to $25.5 \%$ ). This latter improvement was largely driven by the improvement in dietary diversity, as there was no significant improvement in minimum meal frequency (RR $1.02,95 \%$ CI 0.94 to 1.12 ).

\section{Exploratory analysis}

We performed an exploratory analysis using a hierarchical linear regression model to estimate changes in 


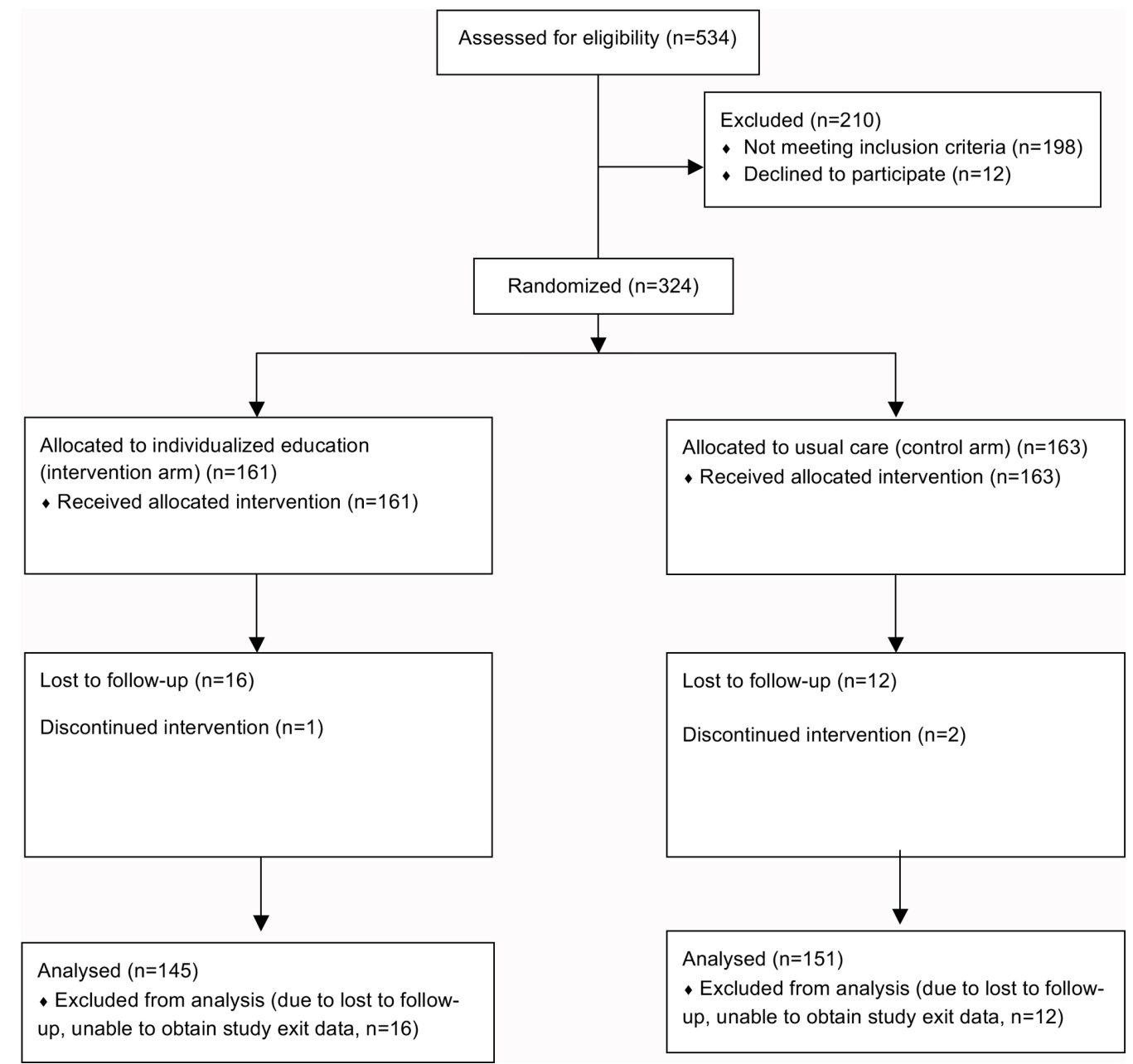

Figure 1 Subject enrolment, randomisation and follow-up.

LAZ/HAZ as a function of important covariates, while controlling for within-subject correlation. Our final model included time, gender, study arm, age at enrolment, family poverty score and number of children under 5 years (online Supplementary table 3; BreuschPagan Lagrange multiplier test for superiority of the hierarchical model versus linear regression, $\mathrm{X}^{2}=255.42$, $p=0.00)$. We found that female gender predicted improved growth (change in LAZ/HAZ) at 6 months of $0.30 \mathrm{SD}$ ( $95 \%$ CI 0.15 to $0.45 ; \mathrm{p}=0.000$ ). Furthermore, every positive point change in the family poverty score (possible score range of 0-100; observed range 0-70, median 28 (IQR 21-34)) predicted an improvement in change in LAZ/HAZ at 6 months of $0.01 \mathrm{SD}(95 \% \mathrm{CI}$ 0.001 to $0.016 ; \mathrm{p}=0.02)$. There was a non-significant trend towards worse growth as the number of children under-five in the household increased (change in LAZ/ HAZ of $-0.12(95 \%$ CI -0.29 to $0.04 ; \mathrm{p}=0.14)$ for two children and -0.24 (95\% CI -0.49 to $0.002, \mathrm{p}=0.05) \mathrm{SD}$ for three or more children).

For exploratory analysis of feeding indicators, we compared change in dietary diversity stratified by age group at baseline (6-11, 12-17, 18-24 months) . Improvements in dietary diversity in the intervention arm were due to changes in the younger age categories, with no significant change in the 18-24 month group (online Supplementary table 4). We also examined changes in consumption of individual food groups in the dietary recall (online Supplementary table 5), noting significant increased daily consumption of legumes and vitamin A-rich fruits and vegetables and a near-significant increase in the consumption of eggs.

\section{DISCUSSION}

We designed this trial in response to endemic poor dietary quality indicators among rural, indigenous Maya children in Guatemala. ${ }^{911-13}$ In particular, we hypothesised that given the agricultural lifestyle of the population and the local availability (but underutilization) of many high-quality foods, an individualised complementary feeding intervention might empower caregivers to better utilise available resources, when compared with the local standard of care of including generic, non-tailored feeding recommendations. Our hypothesis was well supported by the finding that key complementary feeding outcomes, including dietary diversity and overall dietary adequacy (table 3 ) improved in the intervention $\mathrm{arm}$. This improvement in the intervention arm occurred not only for food groups included in the standard food 
Table 1 Baseline demographic and clinical characteristics of study participants

\begin{tabular}{|c|c|c|c|}
\hline Characteristic* & $\begin{array}{l}\text { Individualised education } \\
\text { (intervention) arm }(n=161)\end{array}$ & Usual care arm $(n=163)$ & $P$ values $†$ \\
\hline \multicolumn{4}{|l|}{ Maternal characteristics } \\
\hline Age, years & $26.8 \pm 7.0$ & $27.4 \pm 6.6$ & 0.42 \\
\hline Education, years & $2.2 \pm 2.5$ & $2.3 \pm 2.5$ & 0.69 \\
\hline Literacy, no. (\%) & $85(53)$ & $93(57)$ & 0.44 \\
\hline Parity & $3.5 \pm 2.3$ & $3.3 \pm 2.0$ & 0.38 \\
\hline \multicolumn{4}{|l|}{ Child characteristics } \\
\hline Male, no. (\%) & $92(57)$ & $90(55)$ & 0.73 \\
\hline Age at enrolment, months & 15. $8 \pm 5.2$ & $15.1 \pm 5.2$ & 0.19 \\
\hline Length/height-for-age Z score & $-3.47 \pm 0.73$ & $-3.41 \pm 0.74$ & 0.45 \\
\hline Male & $-3.61 \pm 0.74$ & $-3.54 \pm 0.70$ & 0.56 \\
\hline Female & $-3.29 \pm 0.69$ & $-3.25 \pm 0.76$ & 0.70 \\
\hline One child in the home & $-3.41 \pm 0.77$ & $-3.27 \pm 0.71$ & 0.27 \\
\hline Two children in the home & $-3.47 \pm 0.66$ & $-3.43 \pm 0.73$ & 0.78 \\
\hline$\geq 3$ children in the home & $-3.66 \pm 0.80$ & $-3.72 \pm 0.81$ & 0.81 \\
\hline Weight-for-age Z score & $-1.95 \pm 0.76$ & $-1.92 \pm 0.79$ & 0.73 \\
\hline Weight-for-length/height Z score & $-0.10 \pm 0.91$ & $-0.09 \pm 0.87$ & 0.90 \\
\hline \multicolumn{4}{|l|}{ Feeding practices indicators } \\
\hline Minimum dietary diversity, no. (\%) & $93(58)$ & $80(49)$ & 0.12 \\
\hline Minimum meal frequency, no. (\%) & $133(83)$ & $146(90)$ & 0.07 \\
\hline No maternal education & 47/65 (72) & $50 / 61(82)$ & 0.20 \\
\hline Some maternal education & $86 / 96(90)$ & 96/102 (94) & 0.24 \\
\hline Minimum acceptable diet, no. (\%) & $83(52)$ & $74(45)$ & 0.27 \\
\hline \multicolumn{4}{|l|}{ Household characteristics } \\
\hline Family poverty score & $27.3 \pm 11.4$ & $28.3 \pm 0.2$ & 0.44 \\
\hline Children in household under 5 years & $1.71 \pm 0.75$ & $1.76 \pm 0.67$ & 0.56 \\
\hline
\end{tabular}

*Plus minus values are mean $₫ \pm S D$.

†P values calculated using Student's t-test for continuous variables and the $X^{2}$ test for categorical variables.

ration for both study arms (legumes and eggs) but also for non-supplemented food groups (vitamin A rich fruits and vegetables).

Despite improvement in dietary outcomes, we observed only a non-significant trend towards improved linear growth in the intervention arm (table 2). There are several possible explanations. First, given that our intervention and follow-up were necessarily limited to 6 months by the trial's pragmatic incorporation within an existing nutrition infrastructure, ${ }^{13}$ changes in linear

Table 2 Key growth outcomes

\begin{tabular}{|c|c|c|c|}
\hline Characteristic* & $\begin{array}{l}\text { Individualised education } \\
\text { (intervention) arm }(n=145)\end{array}$ & $\begin{array}{l}\text { Usual care } \\
\text { arm }(n=151)\end{array}$ & Difference $(95 \% \mathrm{Cl})$ \\
\hline Change in length/height-for-age Z score & $0.05 \pm 0.48$ & $-0.02 \pm 0.45$ & $0.07(-0.04$ to 0.18$)$ \\
\hline Male & $0.07 \pm 0.48$ & $-0.01 \pm 0.48$ & $0.06(-0.09$ to 0.21$)$ \\
\hline Female & $0.01 \pm 0.48$ & $0.07 \pm 0.42$ & $0.08(-0.07$ to 0.24$)$ \\
\hline One child in the home & $0.03 \pm 0.48$ & $-0.05 \pm 0.45$ & $-0.02(-0.18$ to 0.15$)$ \\
\hline Two children in the home & $0.06 \pm 0.48$ & $0.06 \pm 0.44$ & $0.12(-0.04$ to 0.28$)$ \\
\hline$\geq 3$ children in the home & $0.03 \pm 0.51$ & $-0.11 \pm 0.49$ & $0.14(-0.18$ to 0.46$)$ \\
\hline Change in weight-for-age $Z$ score & $-0.10 \pm 0.45$ & $-0.18 \pm 0.45$ & $0.08(-0.02$ to 0.19$)$ \\
\hline Change in weight-for-length/height Z score & $-0.23 \pm 0.70$ & $-0.31 \pm 0.69$ & $0.08(-0.08$ to 0.24$)$ \\
\hline
\end{tabular}

*Plus minus values are means \pm SD. 
Table 3 Feeding indicator outcomes

\begin{tabular}{|c|c|c|c|c|}
\hline Characteristic & $\begin{array}{l}\text { Individualised education } \\
\text { (intervention) arm }(n=145)\end{array}$ & $\begin{array}{l}\text { Usual care arm } \\
(n=151)\end{array}$ & Risk ratio $(95 \% \mathrm{Cl})$ & $\begin{array}{l}\text { Risk difference } \\
(95 \% \mathrm{Cl})\end{array}$ \\
\hline Minimum dietary diversity, no. (\%) & $135(93.1)$ & $115(76.2)$ & $1.22(1.11$ to 1.35$)$ & 16.9 (8.9 to 25.0$)$ \\
\hline Minimum meal frequency, no. (\%) & $129(89.0)$ & $131(86.8)$ & $1.02(0.94$ to 1.12$)$ & $2.2(-5.2$ to 9.7$)$ \\
\hline No maternal education & $54 / 60(90.0)$ & $51 / 55(92.7)$ & $0.97(0.87$ to 1.09$)$ & $-2.7(-13.2$ to 7.8$)$ \\
\hline Some maternal education & $75 / 85(88.2)$ & 80/96 (83.3) & $1.06(0.94$ to 1.19$)$ & $4.9(-5.4$ to 15.2$)$ \\
\hline Minimum acceptable diet, no. (\%) & $123(84.8)$ & $104(68.9)$ & $1.23(1.08$ to 1.40$)$ & $15.9(6.4$ to 25.5$)$ \\
\hline
\end{tabular}

growth may have lagged observed improvements in diet. Second, the study was based on existing local priorities at the participating institution and therefore only enrolled subjects with a LAZ/HAZ of less than or equal to $-2.5 \mathrm{SD}$. As such, the intervention impact may have been lower than in a less growth-restricted cohort. Third, the mean age at enrolment was around 15 months, relatively late for many children given the critical 'First Thousand Days' window from conception through 2 years of age, and the fact that prior studies from Guatemala demonstrate very early onset of stunting, including often at birth. ${ }^{22} 23$ However, as a complementary feeding intervention, only children older than 6 months could be engaged here at the time of feeding initiation. In addition, the increasing prevalence of more severe stunting in our cohort over 2 years of life, as also documented elsewhere ${ }^{24}$ meant that proportionately more older children were enrolled.

Another important explanation is related to the delivery of interventions for the usual care arm. As we planned the trial, usual care was intended to be delivered by an existing public sector rural outreach programme. However, allegations of corruption within this programme led to its closure before our trial began. ${ }^{25}$ Therefore, our institutional partner (MHA) leadership and CHWs agreed to also implement the usual care arm. Since MHA conducts all activities using home visits (rather than the public-sector facility-based approach), the quality of 'usual care' we observed may have been greater than anticipated, leading to less than expected growth faltering in the control arm, obscuring the difference between study arms.

Our study has several additional limitations. First, dietary indicators were measured using dietary recall, a method prone to performance improvement with retesting. In addition to the randomised design, we took some measures to mitigate this, including blinding staff performing the recall to subject's allocation. At the same time, although complementary feeding indicators-especially dietary diversity-are strong predictors of stunting in many studies, recently some investigators have questioned the predictive value of dietary diversity as a binary indicator, within the context of a limited 24 hours dietary recall such as we performed. ${ }^{26-29}$

Second, we monitored adherence to study visits and distribution of elements of usual care (micronutrients, food rations), but we did not directly assess consumption.
The WHO dietary recall method we utilised enumerates meal frequency and number of food groups consumed per day, but it does not permit quantification of subjectlevel energy, protein and micronutrient intake. ${ }^{17}$ Additionally, our study was performed in a rural indigenous context in Guatemala, with some of the highest rates of stunting and dietary insufficiency in the world; the results may not be generalisable to other cultural contexts or to populations with different background rates of food insecurity or stunting. Furthermore, although loss to follow-up was minimal, subjects lost to follow-up had significantly different LAZ/HAZ and WLZ/WHZ at baseline than those who completed the study which may have biased our analysis. Finally, the individual counselling model evaluated here is resource intensive and may not be feasible at scale depending on locally available resources.

Despite these limitations, the study provides proof-ofconcept that frontline CHWs in a low-resource setting can deliver a complex, individualised nutrition education intervention to caregivers, resulting in significant improvements to their children's dietary quality, as compared with usual complementary feeding education activities. Our study contributes to the literature on complementary feeding education interventions in low-income and middle-income countries, where it remains a cornerstone of stunting prevention and treatment efforts. ${ }^{3-5}$ From the perspective of a self-efficacy theory of behaviour change, an individualised approach to caregiver education may better engage the caregiver in problem-solving and creative resource utilisation, leading to more effective behaviour change and improved feeding practices. ${ }^{30}$ In fact, in higher-income settings, individualised assessments and caregiver counselling for children with undernutrition have long been the standard of care. ${ }^{31} 32$

Additionally, the finding from our exploratory analysis that dietary diversity improved most significantly in younger age groups broadly supports the First Thousand Days policy framework for addressing chronic early child malnutrition, which emphasises that earlier interventions have greater impact. ${ }^{33-35}$ Furthermore, the finding that individualised education improved consumption of supplemented foods (legumes and eggs) in the intervention arm suggests that the impact of food rations, which are a widely used global strategy to combat child food 
insecurity, can be improved through enhanced caregiver education. The trend towards improved egg consumption is especially interesting, given another recent publication showing their importance for complementary feeding interventions. ${ }^{36}$ Finally, the intervention also improved intake of vitamin A-rich foods, which were not supplemented, suggesting that the enhanced education also acted independently of food supplementation to improve utilisation of local food resources by caregivers. No improvement in the consumption of foods that are not typically available due to cost and which were not supplemented in the ration (dairy, flesh foods) is also consistent with this conclusion.

To our knowledge, this is the first report of such an individualised programme or of the programmatic use of dietary recall instruments by CHW in a low-resource setting. Currently, our group is planning re-enrolment of this study cohort to see if a growth benefit emerges with longer follow-up. Other research priorities include examining the impact of longer-duration interventions and expanding the intervention to stunting prevention programmes.

Acknowledgements We thank the subjects, their families and communities for their participation in this study. We thank Georgina Lopez, Magali Batz, Rosa Tecun, Yolanda Raquec, Yolanda Juarez, Nely Saquec and Lesly Coy for their work on the study. We thank Daniel Tse, Katia Levine and Chase Adam at Watsi and Katia Cnop and Jessica Hawkins at Maya Health Alliance for their assistance with treatment funding. We thank the doctoral students Patricia Rodas, Meri Lubina and Sayra Cardona from Universidad del Valle de Guatemala for their assistance in the study.

Contributors BM designed the study, acquired study data, analysed study data and drafted the manuscript. MFW, MPG and PR designed the study and critically revised the manuscript. AG acquired study data and critically revised the manuscript. KD analysed study data and critically revised the manuscript.

Funding This work was supported by Grand Challenges Canada, grant number SB-1726251050.

Competing interests This work was financially supported by a grant from Grand Challenges Canada to PR and MPG; BM, MFW and PR are current staff members and $\mathrm{KD}$ is a former staff member at Maya Health Alliance, the partnering healthcare organisation for this study in Guatemala.

Patient consent Not required.

Ethics approval Wuqu' Kawoq I Maya Health Alliance; Universidad del Valle de Guatemala

Provenance and peer review Not commissioned; externally peer reviewed.

Data sharing statement Replication data set and statistical code for this study available upon publication at: doi:10.7910/DVN/1MVDY7

Open Access This is an Open Access article distributed in accordance with the Creative Commons Attribution Non Commercial (CC BY-NC 4.0) license, which permits others to distribute, remix, adapt, build upon this work non-commercially, and license their derivative works on different terms, provided the original work is properly cited and the use is non-commercial. See: http://creativecommons.org/ licenses/by-nc/4.0/

(c) Article author(s) (or their employer(s) unless otherwise stated in the text of the article) 2018. All rights reserved. No commercial use is permitted unless otherwise expressly granted.

\section{REFERENCES}

1. Black MM, Walker SP, Fernald LCH, et al. Early childhood development coming of age: science through the life course. Lancet 2017;389:77-90.

2. Lu C, Black MM, Richter LM. Risk of poor development in young children in low-income and middle-income countries: an estimation and analysis at the global, regional, and country level. Lancet Glob Health 2016;4:e916-22.

3. Bhutta ZA, Das JK, Rizvi A, et al. Evidence-based interventions for improvement of maternal and child nutrition: what can be done and at what cost? Lancet 2013;382:452-77.

4. Bhutta ZA, Ahmed T, Black RE, et al. What works? Interventions for maternal and child undernutrition and survival. Lancet 2008;371:417-40.

5. Dewey KG, Adu-Afarwuah S. Systematic review of the efficacy and effectiveness of complementary feeding interventions in developing countries. Matern Child Nutr 2008;4(Suppl 1):24-85.

6. Lassi ZS, Das JK, Zahid G, et al. Impact of education and provision of complementary feeding on growth and morbidity in children less than 2 years of age in developing countries: a systematic review. BMC Public Health 2013;13(Suppl 3):10.

7. Ministerio de Salud Pública y Asistencia Social. VI Encuesta Nacional de Salud Materno Infantil. Guatemala City, Guatemala: Ministerio de Salud Pública y Asistencia Social, 2015.

8. Chary A, Messmer S, Sorenson E, et al. The normalization of childhood disease: an ethnographic study of child malnutrition in rural Guatemala. Hum Organ 2013;72:87-97.

9. Black RE, Victora CG, Walker SP, et al. Maternal and child undernutrition and overweight in low-income and middle-income countries. Lancet 2013;382:427-51.

10. Food and Nutritional Assistance III Project. Summary report: development of evidence-based dietary recommendations for children, pregnant women, and lactating women living in the Western Highlands in Guatemala. Washington, D C: Food and Nutritional Assistance III Project, 2013.

11. Brown K, Henretty N, Chary A, et al. Mixed-methods study identifies key strategies for improving infant and young child feeding practices in a highly stunted rural indigenous population in Guatemala. Matern Child Nutr 2016:12:262-77.

12. Webb MF, Chary AN, De Vries TT, et al. Exploring mechanisms of food insecurity in indigenous agricultural communities in Guatemala: a mixed methods study. BMC Nutr 2016;2:55.

13. Martinez B, Flood D, Cnop K, et al. Improving infant and young child nutrition in a highly stunted rural community: a practical case study from Guatemala. In: Preedy V, Patel V, eds. Handbook of famine, starvation, and nutrient deprivation. Cham, ZG: Springer. (Published Online First: 27 Jun 2017).

14. WHO Multicentre Growth Reference Study Group. WHO child growth standards based on length/height, weight and age. Acta Paediatr Supp/ 2006;450:76-85.

15. Harris PA, Taylor R, Thielke R, et al. Research electronic data capture (REDCap) - a metadata-driven methodology and workflow process for providing translational research informatics support. J Biomed Inform 2009;42:377-81.

16. Cogill B. Anthropometric indicators measurement guide. Washington, D C: Food and Nutrition Technical Assistance Project, 2003.

17. World Health Organization. Indicators for assessing infant and young child feeding practices. Washington, D C: World Health Organization, 2007.

18. Contreras M, Palomino C. Elaboración y Mantenimiento de Infantómetros y Tallímetros de Madera. Lima, Peru: Instituto Nacional de Salud/UNICEF, 2007.

19. Government of Guatemala. Plan de pacto hambre cero. Guatemala City, Guatemala: Government of Guatemala, 2012.

20. Schreiner M, Woller G. Simple Poverty Scorecard, Guatemala. 2010 http://www.microfinance.com/English/Papers/Scoring_Poverty_ Guatemala_EN_2006.pdf (accessed 7 Oct 2017).

21. West BT, Welch KB, Galecki AT. Linear mixed models: a practical guide using statistical software. Boca Raton, FL: CRC Press 2014:P440.

22. Berngard SC, Berngard JB, Krebs NF, et al. Newborn length predicts early infant linear growth retardation and disproportionately high weight gain in a low-income population. Early Hum Dev 2013;89:967-72.

23. Solomons NW, Vossenaar M, Chomat AM, et al. Stunting at birth: recognition of early-life linear growth failure in the western highlands of Guatemala. Public Health Nutr 2015;18:1737-45.

24. Krebs NF, Mazariegos M, Chomba E, et al. Randomized controlled trial of meat compared with multimicronutrient-fortified cereal in infants and toddlers with high stunting rates in diverse settings. Am J Clin Nutr 2012;96:840-7.

25. Avila C, Bright R, Gutierrez JC, et al. Guatemala health system assessment. Bethesda MD: Health Finance \& Governance Project, Abt Associates Inc, 2015.

26. Marriott BP, White A, Hadden L, et al. World Health Organization (WHO) infant and young child feeding indicators: associations with 
growth measures in 14 low-income countries. Matern Child Nutr 2012;8:354-70.

27. Rah JH, Akhter N, Semba RD, et al. Low dietary diversity is a predictor of child stunting in rural Bangladesh. Eur $\mathrm{J}$ Clin Nutr 2010;64:1393-8.

28. Arimond M, Ruel MT. Dietary diversity is associated with child nutritional status: evidence from 11 demographic and health surveys. J Nutr 2004;134:2579-85.

29. Saaka M, Wemakor A, Abizari AR, et al. How well do WHO complementary feeding indicators relate to nutritional status of children aged 6-23 months in rural Northern Ghana? BMC Public Health 2015:15:1157.

30. Bandura A. Self-efficacy mechanism in human agency. Am Psychol 1982;37:122-47.

31. Black MM, Dubowitz H, Hutcheson J, et al. A randomized clinical trial of home intervention for children with failure to thrive. Pediatrics 1995:95:807-14.
32. Kirkland RT, Motil KJ, Duryea TK. Failure to thrive (undernutrition) in children younger than two years: management. In: Kleinman RE, Greer FR, eds. Pediatric Nutrition. Elk Grove, IL: American Academy of Pediatrics, 2014

33. Cunha AJ, Leite ÁJ, Almeida IS. The pediatrician's role in the first thousand days of the child: the pursuit of healthy nutrition and development. J Pediatr 2015;91:S44-51.

34. Koletzko B, Brands B, Chourdakis M, et al. The Power of programming and the EarlyNutrition project: opportunities for health promotion by nutrition during the first thousand days of life and beyond. Ann Nutr Metab 2014;64:187-96.

35. Agosti M, Tandoi F, Morlacchi L, et al. Nutritional and metabolic programming during the first thousand days of life. Pediatr Med Chir 2017;39:157.

36. lannotti LL, Lutter CK, Stewart CP, et al. Eggs in early complementary feeding and child growth: a randomized controlled trial. Pediatrics 2017; 140:e20163459. 